\title{
Use of a recombinant Salmonella enterica serovar Typhimurium strain expressing C-Raf for protection against C-Raf induced lung adenoma in mice
} Ivaylo Gentschev* ${ }^{* \dagger 1}$, Joachim Fensterle ${ }^{\dagger 1}$, Andreas Schmidt ${ }^{\dagger 1}$
Tamara Potapenko $^{1}$, Jakob Troppmair ${ }^{2}$, Werner Goebel ${ }^{3}$ and Ulf R Rapp ${ }^{1}$

Address: ${ }^{1}$ Institut für Medizinische Strahlenkunde und Zellforschung (MSZ), University of Wuerzburg, D-97078 Wuerzburg, Germany, ${ }^{2}$ DanielSwarovski-Research Laboratory, Department of General and Transplant Surgery, Innsbruck Medical University, Innsbruck, Austria and ${ }^{3}$ Department of Microbiology, University of Wuerzburg, D-97074 Wuerzburg, Germany

Email: Ivaylo Gentschev* - ivaylo.gentschev@mail.uni-wuerzburg.de; Joachim Fensterle - joachim.fensterle@mail.uni-wuerzburg.de; Andreas Schmidt - Tumorvaccine@aol.com; Tamara Potapenko - t.potapenko@mail.uni-wuerzburg.de;

Jakob Troppmair - jakob.troppmair@uibk.ac.at; Werner Goebel - goebel@biozentrum.uni-wuerzburg.de; Ulf R Rapp - rappur@mail.uniwuerzburg.de

* Corresponding author †Equal contributors

Published: 09 February 2005

BMC Cancer 2005, 5:15 doi:10.1186/147|-2407-5-15
Received: 15 September 2004

Accepted: 09 February 2005

This article is available from: http://www.biomedcentral.com/I47/-2407/5//5

(c) 2005 Gentschev et al; licensee BioMed Central Ltd.

This is an Open Access article distributed under the terms of the Creative Commons Attribution License (http://creativecommons.org/licenses/by/2.0), which permits unrestricted use, distribution, and reproduction in any medium, provided the original work is properly cited.

\begin{abstract}
Background: Serine-threonine kinases of the Raf family (A-Raf, B-Raf, C-Raf) are central players in cellular signal transduction, and thus often causally involved in the development of cancer when mutated or over-expressed. Therefore these proteins are potential targets for immunotherapy and a possible basis for vaccine development against tumors. In this study we analyzed the functionality of a new live C-Raf vaccine based on an attenuated Salmonella enterica serovar Typhimurium aroA strain in two Raf dependent lung tumor mouse models.
\end{abstract}

Methods: The antigen C-Raf has been fused to the C-terminal secretion signal of Escherichia coli $\alpha$-hemolysin and expressed in secreted form by an attenuated aroA Salmonella enterica serovar Typhimurium strain via the $\alpha$-hemolysin secretion pathway. The effect of the immunization with this recombinant C-Raf strain on wild-type C57BL/6 or lung tumor bearing transgenic BxB mice was analyzed using western blot and FACS analysis as well as specific tumor growth assays.

Results: C-Raf antigen was successfully expressed in secreted form by an attenuated Salmonella enterica serovar Typhimurium aroA strain using the $E$. coli hemolysin secretion system. Immunization of wild-type C57BL/6 or tumor bearing mice provoked specific C-Raf antibody and T-cell responses. Most importantly, the vaccine strain significantly reduced tumor growth in two transgenic mouse models of Raf oncogene-induced lung adenomas.

Conclusions: The combination of the C-Raf antigen, hemolysin secretion system and Salmonella enterica serovar Typhimurium could form the basis for a new generation of live bacterial vaccines for the treatment of Raf dependent human malignancies. 


\section{Background}

The Raf proteins (A-Raf, B-Raf, C-Raf) are located upstream of MEK and downstream of Ras and represent an essential part of the mitogenic cascade [1-3]. Interestingly, Raf kinases are not only central players in cellular signal transduction, but are often causally involved in the development of cancer. Recently, B-Raf was found to be mutated in a broad range of malignancies including melanoma (more than 65\%), and colon cancer [4]. In addition, overexpression of C-Raf was found in many tumors $[5,6]$. Therefore, these proteins are potential targets for immunotherapy as well as immunoprevention of tumors.

Here we describe the development of a C-Raf vaccine on the basis of an attenuated Salmonella enterica serovar Typhimurium aroA strain. Such recombinant live vaccines have been shown to efficiently elicit both, humoral and cellular immune responses against a variety of heterologous antigens $[7,8]$. In order to achieve stable expression of C-Raf we used the E. coli $\alpha$-hemolysin (HlyA) secretion system which is fully active in Salmonella [9]. This transport machinery is the prototype of type I secretion systems and consists of three different components, namely HlyB, HlyD and TolC. The HlyA carries at its C-terminus a secretion signal of about 50-60 amino acids in length ( $\mathrm{HlyA}_{\mathrm{s}}$ ), which is recognized by the HlyB/HlyD/TolC-translocator, leading to direct secretion of the entire protein into the extracellular medium without the formation of periplasmic intermediates. In addition, fused to the C-terminus of heterologous proteins, the $\mathrm{HlyA}_{\mathrm{s}}$ leads to efficient secretion of such proteins by the recombinant bacteria. In our case, the whole C-Raf antigen fused to the C-terminal secretion signal of hemolysin was efficiently expressed and secreted by an attenuated Salmonella enterica serovar Typhimurium aroA strain. The effects of this recombinant vaccine were assessed in wild-type $\mathrm{C} 57 \mathrm{BL} / 6$ or tumor bearing transgenic $\mathrm{BxB}$ mice.

\section{Methods}

\section{Bacterial strains, plasmids, cell lines and mice}

The bacterial strains, plasmids, cell lines and mice used in this study are listed in Table 1.

\section{Plasmid transformation in Salmonella enterica serovar Typhimurium SL7207}

The plasmids pMOhly1 and pMOhly-Raf were first transformed in competent Salmonella enterica serovar Typhimurium LB5000 (Tab. 1), a restriction-negative and modification-proficient strain by a standard transformation protocol for E. coli $[10,11]$. Subsequently, the plasmids purified from Salmonella enterica serovar Typhimurium LB5000 were introduced into Salmonella enterica serovar Typhimurium SL7207 by electroporation using a Bio-Rad Gene Pulser (Hercules, CA, USA) at 2.5
$\mathrm{kV}, 25$ microfarads $(\mu \mathrm{F})$, and $200 \mathrm{Ohm}$ in a $0.1 \mathrm{~cm}$ electroporation cuvette.

\section{Construction of the plasmid pMOhly-Raf}

Sense primer 5' Raf: 5'-ATGGAGCACATACATGCATCTTGGAAG-3' and antisense primer 3'Raf: 5'-CAACTAGAATGCATGCAGCCTCGGGGA-3' were used to amplify by PCR a 1950 bp DNA fragment representing the entire craf gene from plasmid pUC13-c-raf-1 [12]. PCRs were performed in a Thermal Cycler 60 (Biometra, Göttingen, Germany) for 30 cycles of $94^{\circ} \mathrm{C}$ for $1 \mathrm{~min}, 55^{\circ} \mathrm{C}$ for $1 \mathrm{~min}$, and $72^{\circ} \mathrm{C}$ for $90 \mathrm{~s}$. After purification with the GeneClean Kit (Bio101, La Jolla, Ca) and digestion with the NsiI restriction enzyme, the DNA fragment carrying the craf gene was inserted into the single NsiI site of the export vector pMOhly1 [13]. The resulting plasmid pMOhly-Raf was isolated from E. coli DH5 $\alpha$ (Invitrogen), analyzed and transformed in S. typhimurium SL7207 (Tab. 1) by electroporation.

\section{Western blot analysis}

Salmonella enterica serovar Typhimurium strains harbouring the recombinant plasmids pMOhly1 or pMOhly-Raf were cultivated at $37^{\circ} \mathrm{C}$ in BHI medium with $100 \mu \mathrm{g} / \mathrm{ml}$ ampicillin. Cells at the exponential growth phase $\left(\mathrm{OD}_{600}\right.$ of 1 ) were centrifuged at $5000 \times \mathrm{g}$ at $4{ }^{\circ} \mathrm{C}$ for $5 \mathrm{~min}$. The supernatant proteins were precipitated with $10 \%(\mathrm{~V} / \mathrm{V})$ trichloroacetic acid (TCA) for $1 \mathrm{~h}$ on ice, collected by centrifugation and resuspended in SDS sample buffer. The supernatant proteins were separated on $10 \%$ gels by SDSPAGE [14]. For immunodetection of Raf-HlyA proteins the rabbit polyclonal anti-Raf antibody SP-63 (diluted 1:1,000, Rapp Laboratory) and donkey anti-rabbit immunoglobulins linked to horseradish peroxidase (Amersham Pharmacia Biotech) diluted 1:1,000 as secondary antibodies were used. Blots were developed by enhanced chemiluminescence (ECL reagents; Amersham Biosciences, UK) and exposed on X-ray film (Kodak, XO-MAT-AR) for 1 $\min$.

\section{Immunization of mice with Salmonella enterica serovar Typhimurium SL7207 strains}

Oral/intravenous prime boost protocol (p.o./i.v.)

In order to achieve a broad immune response encompassing both, the mucosal and systemic immunity against CRaf, we combined oral immunization (p.o.) with an intravenous (i.v.) boost. In these experiments, seven weeks old C57BL $/ 6$ or BxB23 mice were immunized, first p.o. three times with $5 \times 10^{9}$ bacteria/100 $\mu \mathrm{l}$ phosphate-bufferd saline (PBS) at 5-day intervals. At day 45 after the start of the vaccination, these mice were boosted intravenously (i.v.) with a single-dose of $5 \times 10^{5}$ bacteria/100 $\mu \mathrm{l}$ PBS. The BxB23 mice received a second i.v. boost of $5 \times 10^{5} \mathrm{bac}-$ teria at day 90 after the start of the vaccination. Induction 
Table I: Bacterial strains, plasmids (Ap ${ }^{\mathrm{R}}$-ampicillin-resistant), cell lines and mice

\begin{tabular}{|c|c|c|}
\hline Name & Relevant characteristics/sequence & Source or reference \\
\hline \multicolumn{3}{|l|}{ Bacterial strains: } \\
\hline E. coli $\mathrm{DH} 5 \alpha$ & 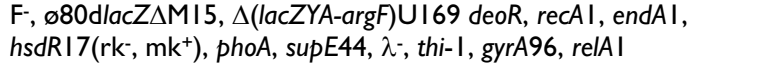 & Takaba \\
\hline \multicolumn{3}{|l|}{ Salmonella enterica serovar } \\
\hline Typhimurium aroA SL7207 & hisG46, DEL407 [aroA544::Tn I0 $\left.\left(\mathrm{Tc}^{\mathrm{s}}\right)\right]$ & Stocker, B. A. D. \\
\hline \multicolumn{3}{|l|}{ Salmonella enterica serovar } \\
\hline Typhimurium LB5000 & $\mathrm{rk}^{-}, \mathrm{mk}^{+}$ & Stocker, B. A. D. \\
\hline \multicolumn{3}{|l|}{ Plasmids: } \\
\hline pUCI3-c-raf-I & c-raf cDNA in $\mathrm{pUCl} 3$ & {$[12]$} \\
\hline pcDNA3 & PCMV, ApR, Neomycin, SV 40, ColE & Invitrogene \\
\hline pcDNA-craf & craf cDNA in pcDNA3 & Troppmair, J \\
\hline pMOhlyl & $\begin{array}{l}\text { ApR, hlyR, hlyC, hlyAs (encoding the hemolysin secretion signal), } \\
\text { hlyB, hlyD }\end{array}$ & [13] \\
\hline pMOhly-Raf & $\begin{array}{l}\text { Ap } p^{R} \text {, hlyR, hlyC, raf-hlyAs (encoding a C-Raf-hemolysin fusion), hlyB, } \\
\text { hlyD }\end{array}$ & this study \\
\hline \multicolumn{3}{|l|}{ Cell lines: } \\
\hline EL-4 & spontaneous murine lymphoma & ATCC(Rockville, MD, USA) \\
\hline EL-4Raf & pcDNA-craf transfected EL-4 cells & this study \\
\hline SF9 & insect cell line & Gibco \\
\hline SF9 Raf & craf transfected SF9 cells & {$[28]$} \\
\hline \multicolumn{3}{|l|}{ Mice: } \\
\hline C57BL/6JolaHsd & wild-type $\left(\mathrm{H}-2^{\mathrm{b}}\right)$ & Harlan-Winkelmann, Borche, Germany \\
\hline $\mathrm{B} \times \mathrm{B} 23$ & $\begin{array}{l}{\left[(\mathrm{C} 57 \mathrm{BL} / 6 \times \mathrm{DBA}-2) \mathrm{F}_{1}\right] \text { expressing an oncogenically activated }} \\
\mathrm{NH}_{2} \text {-terminal deletion mutant } \mathrm{c}-\mathrm{Raf}-\mathrm{I}-\mathrm{B} \times \mathrm{B} \text { under the control of } \\
\text { human } \mathrm{SP}-\mathrm{C}_{\text {promoter }}\end{array}$ & {$[15]$} \\
\hline $\mathrm{BxBII}$ & $\begin{array}{l}{\left[(\mathrm{C} 57 \mathrm{BL} / 6 \times \mathrm{DBA}-2) \mathrm{F}_{1}\right] \text { expressing an oncogenically activated }} \\
\mathrm{NH}_{2} \text {-terminal deletion mutant } \mathrm{c}-\mathrm{Raf}-\mathrm{I}-\mathrm{B} \times \mathrm{B} \text { under the control of } \\
\text { human } \mathrm{SP}-\mathrm{C} \text { promoter }\end{array}$ & {$[15]$} \\
\hline
\end{tabular}

of Raf-specific immune responses were analyzed at day 50 for C57BL/6 or at day 95 for BxB23 respectively.

\section{Intranasal Immunization (i.n.)}

Seven weeks old BxB23 mice were immunized i.n. four times with $1 \times 10^{7}$ bacteria/30 $\mu$ l phosphate-buffered saline (PBS) at 14-day intervals. The vaccine was applied using a micropipette onto the nares of mice under anesthesia.

Induction of Raf-specific immune responses were analyzed at day 70 .

\section{I. n. Immunization of $B X B \mid$ I mice with Salmonella enterica serovar Typhimurium SL7207/pMOhly-Raf}

Four months old BXB11 mice were immunized i.n. three times with $1 \times 10^{8}$ salmonellae in $10 \mu \mathrm{l}$ PBS at 14-day intervals. The vaccine was applied using a micropipette into the nares of mice without anesthesia.

\section{Construction of a C-Raf overexpressing EL-4 cell line}

In order to create tools for analysis of C-Raf specific T cells we first constructed a C-Raf overexpressing EL-4 cell line (ELRaf). The EL4 tumor cell line is a murine thymoma cell line of the H-2 ${ }^{\mathrm{b}}$ haplotype (Tab. 1). $10 \mu \mathrm{g}$ purified DNA of plasmid pDNA3craf was introduced into EL4 cells by electroporation with the Bio-Rad Gene Pulser (Hercules, CA) at $0.25 \mathrm{kV}, 960 \mu \mathrm{FD}$, in a $0.4-\mathrm{cm}$ electroporation cuvette. The transformed cells were grown RPMI 1640 medium (Invitrogen) supplemented with 5\% (vol/vol) FCS (PAN Systems) and $600 \mu \mathrm{g} / \mathrm{ml} \mathrm{G418} \mathrm{(Sigma).} \mathrm{C-Raf} \mathrm{is} \mathrm{highly}$ expressed in ELRaf cells (data not shown).

\section{Flow cytometric detection of specific CD8 ${ }^{+} T$-cells Isolation of spleen cells}

Animals were sacrificed and a single cell suspension of splenocytes was prepared by passage of the spleen through a sieve into RP 10 medium [RPMI medium (Life Technologies) supplemented with glutamine (1\%), 50 $\mu \mathrm{M} \beta$-mercaptoethanol (ROTH, Wuerzburg), penicillin (10 U/ml, GIBGO), streptomycin (100 U/ml, GIBGO) and $10 \%$ fetal calf serum (PAN ${ }^{\mathrm{TM}}$, BIOTECH GmbH).

The cell suspension was centrifuged and resuspended in 3 $\mathrm{ml}$ lysis buffer ( $5 \mathrm{mM}$ Tris- $\mathrm{HCl}, 140 \mathrm{mM} \mathrm{NH}_{4} \mathrm{Cl}, \mathrm{pH} 7.3$ ) for the lysis of erythrocytes. After 2 minutes, $10 \mathrm{ml}$ RP 10 medium was added to stop lysis. After centrifugation, cells were resuspended in $2 \mathrm{ml} \mathrm{RP} 10$ medium and counted. 


\section{Restimulation}

In $6 \mathrm{ml}$ FACS tubes and a total volume of $100 \mu \mathrm{l}$ RP 10 medium in the presence of $30 \mathrm{U} / \mathrm{ml}$ recombinant IL-2 and $10 \mu \mathrm{g} / \mathrm{ml}$ Brefeldin A at $37^{\circ} \mathrm{C}, 5 \% \mathrm{CO}_{2}, 1 \times 10^{6}$ spleen cells were incubated for 5 hours with $5 \times 10^{5} \mathrm{C}$-Raf overexpressing EL- 4 cells (EL-Raf) or $5 \times 10^{5}$ EL- 4 cells or with the addition of $10 \mathrm{ng} / \mathrm{ml}$ of phorbol myristyl acetate (PMA; Sigma) and $500 \mathrm{ng} / \mathrm{ml}$ of ionomycin (Sigma) or with medium alone.

\section{Staining}

After restimulation, cells were washed with PBS-0.1\% bovine serum albumin (BSA; P-B buffer) and incubated with $1 \mu \mathrm{l}$ of anti-CD8-CyChrome (Pharmingen $\mathrm{Nr}$. $01082 \mathrm{~A}$ ) in a volume of $100 \mu \mathrm{l}$ PBS-0.1\% BSA for $20 \mathrm{~min}$ on ice. Subsequently, cells were washed and fixed for 20 min at room temperature with PBS-2\% paraformaldehyde (Sigma). After washing with PBS-0.1\% (BSA), cells were permeabilized with PBS-0.1\% BSA-0.5\% saponin (Sigma, $\mathrm{P}-\mathrm{B}-\mathrm{S}$ ) buffer. After incubation for $5 \mathrm{~min}$ at room temperature, cells were washed with P-B-S buffer and incubated in a volume of $100 \mu \mathrm{l}$ at room temperature with polyclonal rat immunoglobulin G (IgG) antibodies (JacksonImmunoResearch) to block nonspecific binding and $1 \mu \mathrm{l}$ anti-IFN- $\gamma$-FITC (AN18.17.24; XMG1.2 Rat IgG1; Pharmingen) for $20 \mathrm{~min}$. After incubation, cells were washed twice with P-B-S buffer and another time with PB buffer. Cells were resuspended in $400 \mu \mathrm{l}$ PBS-PFA 0,5\% and kept at $4^{\circ} \mathrm{C}$ until analysis.

\section{Analysis}

Cells were analyzed by flow cytometry in a FACS Calibur flow cytometer (Becton Dickinson) using CellQuest 3.0 software (Becton Dickinson). Lymphocytes were chosen according to their size and granularity in a forward/side scatter diagram. Numbers are expressed as percent IFN- $\gamma$ positive $\mathrm{CD}^{+}$cells.

\section{Statistical analysis}

The statistical significance of differential findings between experimental groups was determined by Student's $t$ test. Findings were regarded as significant, if $P$ values were $<0.05$. Survival curves were compared using a log rank test.

\section{Results}

Creation of a C-Raf vaccine on the basis of the attenuated Salmonella enterica serovar Typhimurium strain SL7207 The construction of the attenuated Salmonella enterica serovar Typhimurium aroA strain SL7207 secreting the CRaf antigen was achieved by cloning the human craf cDNA from pUC13-c-raf-1 [12] into the vector plasmid pMOhly1 [13] as described in materials and methods. The resulting plasmid pMOhly-Raf carried the craf-hlyAs fused gene and the functional $h l y B$ and $h l y D$ genes required for its secretion (Fig. 1). The S. typhimurium SL7207/pMOhlyRaf strain efficiently expressed and secreted the hybrid CRaf protein, as shown by immunoblotting with polyclonal antibodies raised against C-Raf (Fig. 2). The amount of secreted C-Raf was 2-3 $\mu$ g protein/ml supernatant under the experimental conditions.

\section{Raf-specific responses of mice after immunization with recombinant SL7207/pMOhly-Raf}

The efficacy of the recombinant bacterial strain to induce a Raf-specific immune response was analyzed using wildtype $\mathrm{C} 57 \mathrm{BL} / 6$ and transgenic $\mathrm{BxB} 23$ mice. Groups of five $\mathrm{C} 57 \mathrm{BL} / 6$ and BxB23 mice at the age of 7 weeks were immunized p.o./i.v or i.n. with recombinant Salmonella enterica serovar Typhimurium SL7207 secreting C-Raf antigen (SL7207/pMOhly-Raf) and with Salmonella enterica serovar Typhimurium SL7207 as control in order to test the induction of Raf-specific immune responses. The data showed that $20 \%$ of the sera of BxB23 mice immunized with SL7207/pMOhly-Raf contained Raf-specific antibodies (Fig. 3; supplementary Fig. 1 [see Additional file 1]). In contrast, no Raf-specific IgG response was detectable in the sera of $\mathrm{BxB} 23$ mice immunized with SL7207 alone (data not shown). Similar data were obtained after immunization of $\mathrm{C} 57 \mathrm{BL} / 6$ mice with SL7207/pMOhly-Raf and SL7207 (data not shown).

To assess the induction of Raf-specific T-cell responses, mice were sacrificed and Raf specific T-cell responses were assessed using intracellular IFN- $\gamma$ staining followed by FACS analysis. For this purpose, T-cells were restimulated with C-Raf overexpressing EL-4 cells. Using this technique, we could detect Raf specific CD8 ${ }^{+} \mathrm{T}$-cell response in C57BL/6 animals immunized p.o./i.v. with SL7207/ pMOhly-Raf only but not in mice immunized i.n. or with the control strain SL7207 (Fig. 4). In immunized BxB23 mice, but not naïve BxB23 mice, a high background and variability of $\mathrm{CD}^{+}$IFN- $\gamma$ positive cells even with non-specific stimulation was observed in two independent experiments. Therefore it was not possible to assess specific Tcell responses in this setting. Interestingly, the level of Tcells which responded to polyclonal stimulation by PMA / ionomycin was also reduced about 4 fold in comparison to $\mathrm{C} 57 \mathrm{BL} / 6$ mice (data not shown).

\section{Salmonella enterica serovar Typhimurium SL7207/ pMOhly-Raf strain induced partial protection against lung cancer in transgenic mouse models of Raf oncogene- induced lung adenomas}

To test the protective capacity of the immune responses induced by the recombinant Salmonella strains, groups of 6 to 10 heterozygous $\mathrm{BxB} 23$ mice at the age of 7 weeks were immunized p.o./i.v. or i.n. with recombinant Salmonella enterica serovar Typhimurium strain (SL7207/ pMOhly-Raf) or with SL7207 as control. BxB23 mice 


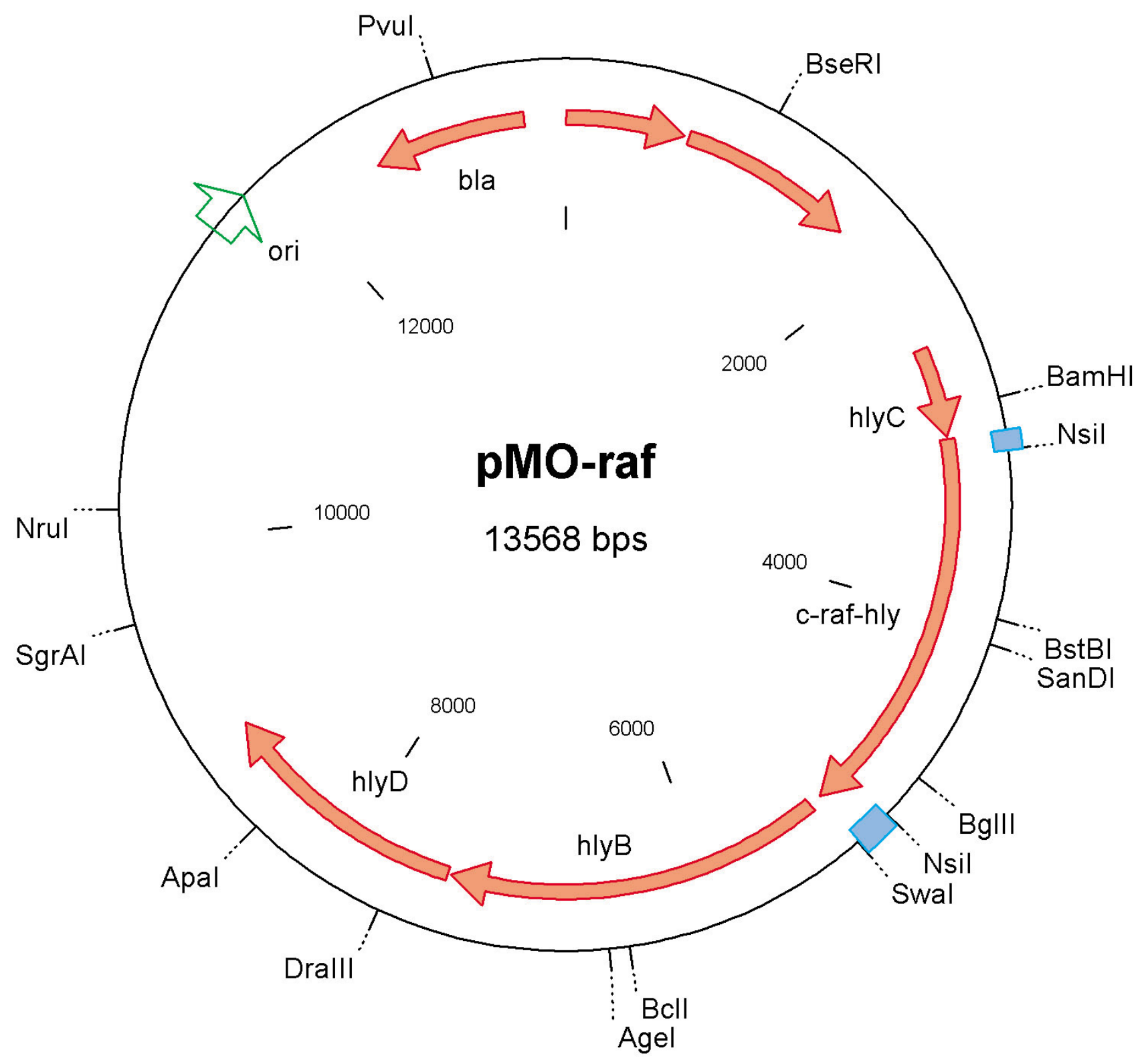

Figure I

Restriction map of plasmid pMOhly-Raf The plasmid pMOhly-Raf contains the intact structural genes $h l y C$, hlyB and $h l y D$ of the hemolysin operon and the c-raf-hlyA fusion hybrid gene. All genes are transcribed from the original cis-acting expression sites in front of hlyC [27]. Abbreviations: ori - origin of replication, bla - ampicillin resistance cassette

normally show an induction of lung adenomas with short latency and at $100 \%$ incidence $[15,16]$. The development of lung adenomas in the vaccinated BxB23 mice was assessed for 13 months. Our analysis revealed a significantly delayed tumor growth (reduction of lung weight) in mice immunized i.n. or p.o./i.v. with SL7207/ pMOhly-Raf compared to control mice (Fig. 5).

In order to confirm these data we repeated the protection experiments using BxB11, another craf transgenic strain, which develop lung adenomas after a shorter latency 


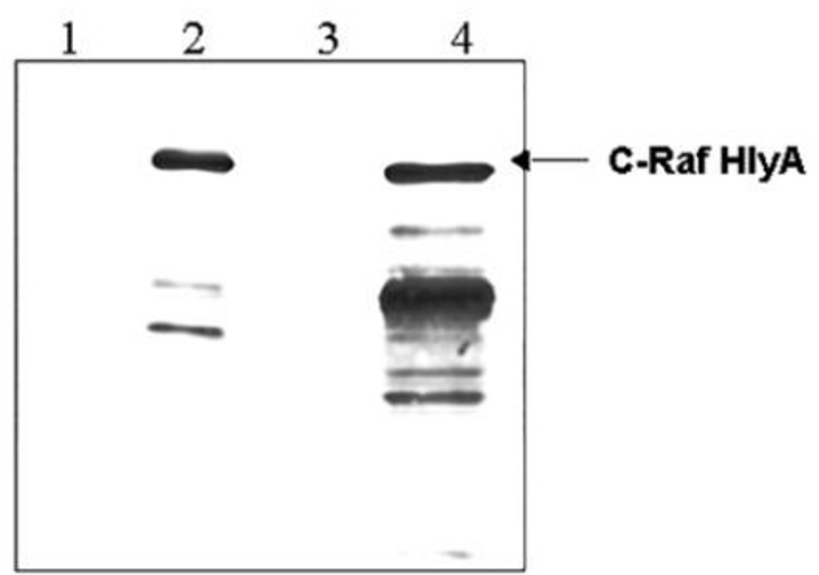

\section{Figure 2}

Identification of the Raf-HlyAs fusion protein by immunoblotting. Cultures of Salmonella enterica serovar Typhimurium SL7207 carrying the plasmids pMOhlyl (lanes I and 3) or pMOhly-Raf (lanes 2 and 4) were grown in $\mathrm{BHI}$ medium to a density of $5 \times 10^{8}$ cells per $\mathrm{ml}$ (optical cell density OD600 = I). Supernatant proteins precipitated from $1.5 \mathrm{ml}$ of bacterial culture were loaded in lanes $I$ and 2; cellular proteins from $0.15 \mathrm{ml}$ of culture were loaded in lanes 3 and 4 . The immunoblot was developed with polyclonal anti C-Raf antibodies. The samplers were prepared as described in Materials and Methods.
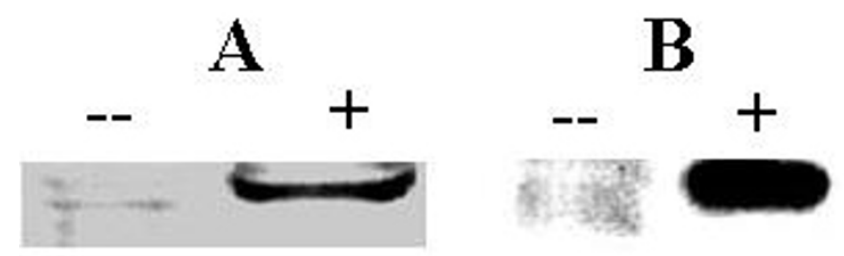

Figure 3

Raf-specific lgG in sera of i.n (A) or p.o/i.v. (B) immunized BxB23 mice (serum dilution I:200) demonstrated by western blotting. Proteins of $10^{6}$ lysed SF9 cells expressing recombinant C-Raf [28] (lanes marked with + ) or proteins of $10^{6}$ lysed SF9 cells (- lanes) as control were loaded per lane.

period compared to BxB23 mice [15]. In this case, $66 \%$ of the mice immunized with SL7207/pMOhly-Raf survived at least three months longer than the control mice (Fig. 6).

These results suggest that the immunization with the vaccine strain SL7207/pMOhly-Raf can achieve a partial protection against tumor growth in the $\mathrm{BxB}$ mouse model.

\section{Discussion}

The major problems for vaccine development against cancer are the heterogeneity of the tumor cells and the fact that all tumor antigens are self-antigens. Therefore specific T-cells might be anergic or tolerant $[17,18]$.

However, despite these problems, several cancer vaccines have already reached clinical trials [19]. The success of these vaccines seems to be dependent on the target antigen and on the tumor type.

Here we describe a new strategy for achieving an antitumor immune response with a C-Raf vaccine on the basis of an attenuated Salmonella enterica serovar Typhimurium aro $A$ strain as a "live vaccine". In general, recombinant aroA salmonellae are efficient live bacterial vectors that stimulate strong mucosal immunity, humoral and cellmediated responses with a great potential as live vaccine carriers in both humans and animals [7,20]. Advantages of live attenuated aroA Salmonella vaccines include their safety and easy administration $[21,22]$. In addition aroA Salmonella enterica serovar Typhimurium strains were already successfully used as carriers for DNA vaccines against cancer in mice [23].

In this study the C-Raf antigen was delivered in secreted form by attenuated Salmonella enterica serovar Typhimurium aroA strain using the $E$. coli hemolysin secretion system. This system allows an efficient antigen secretion and presentation, which are necessary for an optimal immune response against the given heterologous antigen [9]. In fact, immunization of mice with the Salmonella enterica serovar Typhimurium aroA strain SL7207 secreting C-Raf resulted in the induction of a humoral immune response, manifested by the presence of Raf-specific antibodies in some of the vaccinated mice. In addition, C57BL/6 mice immunized with Salmonella enterica serovar Typhimurium SL7207/pMOhly-Raf developed a Raf-specific CD8+ T-cell response. The C-Raf vaccine thus is able to break the peripheral tolerance of the immune system towards C-Raf and to induce a specific immune response. Although the transgenic model is closer to the human setting in comparison to challenge models with tumor cell lines, we can not formally exclude that lung specific expression of the transgene in our $\mathrm{BxB}$ model is not sufficient for the induction of peripheral tolerance. Furthermore, side effects due to autoimmunity might occur in humans who have a more generalized expression pattern. However, the lung tissue does not belong to immunoprivileged sites and we have never observed any signs of lung pathology in immunized animals which strongly suggests that the data could, in principle, be translated into the human setting. 


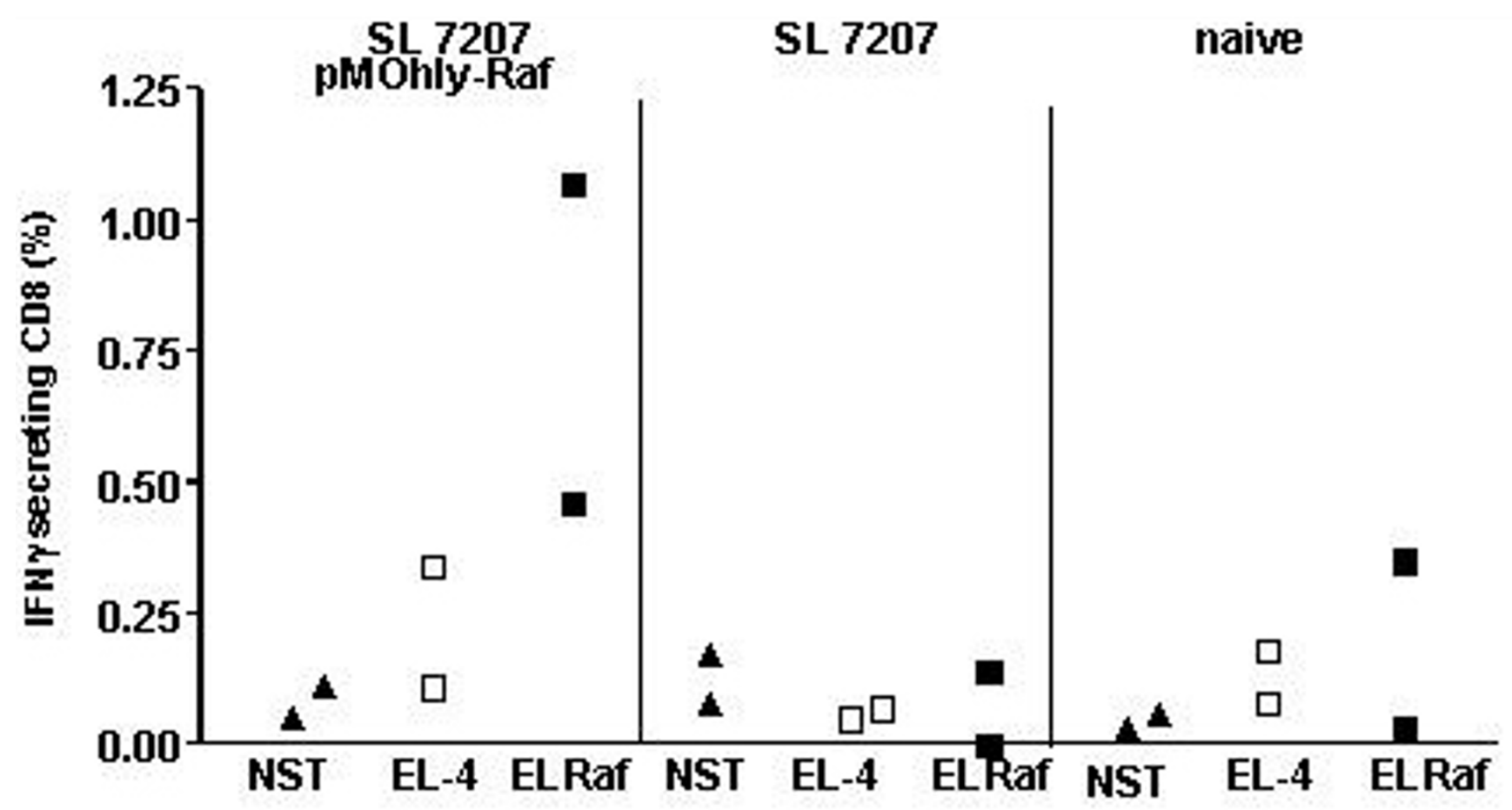

Figure 4

Increased frequency of IFN- $\gamma$-secreting CD8+ T cells after p.o./i.v. Salmonella infection of C57BL/6 mice $(\mathrm{n}=3)$. For each group, I mouse was assessed individually and the remaining splenocytes from 2 mice were pooled in an equivalent proportion. I $\times 10^{6}$ spleen cells restimulated with either wild-type EL-4 (EL-4) or C-Raf overexpressing EL-4 cell (EL-Raf) and not stimulated (NST) were used. Production of IFN- $\gamma$ was determined by flow cytometry after CD8 surface staining and intracellular IFN- $\gamma$ staining. Each data point represents the proportion of IFN- $\gamma$ positive cells for one individual mouse or two pooled mice respectively. Intracellular staining with an FITC-conjugated isotype control mAb always resulted in $<0.05 \%$ positive cells.

We demonstrated also a partial tumor protection both in BxB23 and in BxB11 mice after immunization with recombinant Salmonella enterica serovar Typhimurium SL7207/pMOhly-Raf. However, we were not able to assess Raf specific CTL responses in these mice due to the high variability and background and therefore we cannot conclude whether protection is really due to cytotoxic T-cells or might be the result of other effects, e.g. an increased intratumoral level of IFN- $\gamma$ produced by Raf specific CD4 ${ }^{+}$ T-cells. Interestingly, the observed variation occurred only in treated BxB23 mice, not in naïve BxB23 mice. Therefore, the observed effect might be due to a spontaneous induction of an immune response mediated by tumor infiltrating bacteria. It is interesting to note that spontaneous Raf specific immune responses also occur in the human context, which we have recently demonstrated BRaf V599E specific CTL and B-Raf /B-Raf V599E specific humoral responses in melanoma patients [24,25].
Most importantly, the lack of B-Raf V599E mutations in metastases of melanoma patients with strong B-Raf V599E CD8 response [24] supports the notion that CD8+ T-cells are effective in eliminating antigen positive tumor cells. The combined data thus provide proof of concept for the development of Raf-based anti-cancer vaccines.

This is the first example demonstrating that the E. coli hemolysin secretion system is a versatile tool for the delivery of cancer antigens in Salmonella enterica serovar Typhimurium. Moreover, we have recently shown that this secretion system is also fully active in Salmonella enterica serovar Typhi Ty21a, the only Salmonella vaccine strain registered for human use [26]. Therefore, the combination of the hemolysin secretion system and S. typhi Ty21a could form the basis for a new generation of live bacterial vaccines against cancer. 


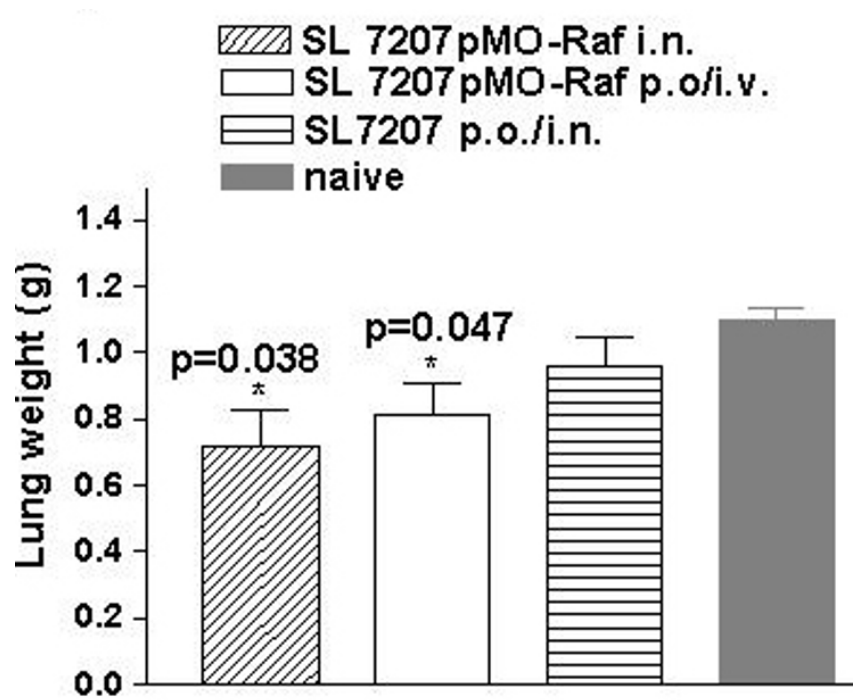

\section{Figure 5}

Effect of immunization on reduction of lung weight. Reduction of lung weight is a mark for a delayed tumor growth. Lung weight of 12-13-month-old BxB23 mice immunized with SL7207/pMO-Raf (i.n., $n=10)$, SL7207/pMO Raf (p.o./ i.v., $n=8)$, SL7207 (i.n or p.o./i.v., $n=6)$ and naive $(n=6)$. Bars represent means and standard deviation of the mice per group. Differences in lung weight (tumor weight) between experimental groups treated with SL7207pMO-Raf (i.n and p.o./i.v.) and all control groups were statistically significant $*$ $(P<0.05)$, as determined by Student's $t$ test. $n$ - number of the mice

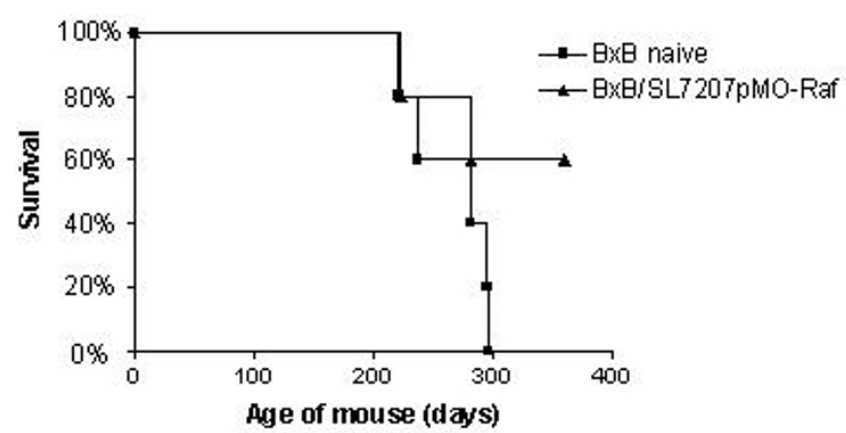

Figure 6

Survival of naive BxBII ( $\square$ ) or BxBII mice immunized intranasally with SL7207 pMOhly-Raf $(\boldsymbol{A})$ in period of one year.

\section{Conclusions}

Taken together we have demonstrated that the C-Raf antigen can be successfully expressed and secreted by the attenuated Salmonella enterica serovar Typhimurium aroA SL7207 strain via the E. coli hemolysin secretion system. In addition, the immunization of wild-type $\mathrm{C} 57 \mathrm{BL} / 6$ or tumor bearing transgenic mice with this C-Raf secreting Salmonella strain provoked specific C-Raf antibody and T cell responses. Most importantly, the vaccine strain induced partial protection against lung cancer in two transgenic mouse models of Raf oncogene-induced lung adenomas.

The approach may provide a new strategy for the rational design of cancer therapies.

\section{Competing interests}

The author(s) declare that they have no competing interests.

\section{Authors' contributions}

IG, JF and JT designed the study. IG drafted the manuscript. JF was also involved in writing the report. AS and JF did the FACS analyses. JT constructed the EL4Raf cell line. TP, AS, JF and IG carried out the immunization of mice and the Western blot analyses. WG and URR were involved in providing the conceptual framework for this study. All authors approved the final version of the manuscript.

\section{Additional material}

\section{Additional File 1}

Supplementary figure 1: C-Raf-specific IgG in sera of p.o/i.v. (A) or i.n (B) immunized BxB23 mice (serum dilution 1:1000) demonstrated by western blotting. Supplementary figure with WESTERN Blot analysis of positive C-Raf sera.

Click here for file

[http://www.biomedcentral.com/content/supplementary/14712407-5-15-S1.pdf]

\section{Acknowledgements}

We would like to thank G. Dietrich and J.C. Becker for helpful discussions and Z. Sokolovic and H. Drexler for critical reading of the manuscript. This work was supported by grants from the Bavarian Research Cooperations Abayfor (Forimmun T3), Theraimmune GmbH (Wuerzburg) and the Fond der Chemischen Industrie.

\section{References}

I. Avruch J, Zhang XF, Kyriakis JM: Raf meets Ras: completing the framework of a signal transduction pathway. Trends Biochem Sci 1994, 19:279-83.

2. Daum G, Eisenmann-Tappe I, Fries HW, Troppmair J, Rapp UR: The ins and outs of Raf kinases. Trends Biochem Sci 1994, 19:474-80.

3. Hagemann C, Rapp UR: Isotype-specific functions of Raf kinases. Exp Cell Res 1999, 253:34-46. 
4. Davies H, Bignell GR, Cox C, Stephens P, Edkins S, Clegg S, Teague J, Woffendin H, Garnett MJ, Bottomley W, Davis N, Dicks E, Ewing R, Floyd Y, Gray K, Hall S, Hawes R, Hughes J, Kosmidou V, Menzies A, Mould C, Parker A, Stevens C, Watt S, Hooper S, Wilson R, Jayatilake H, Gusterson BA, Cooper C, Shipley J, Hargrave D, Pritchard-Jones K, Maitland N, Chenevix-Trench G, Riggins G], Bigner DD, Palmieri G, Cossu A, Flanagan A, Nicholson A, Ho JW, Leung SY, Yuen ST, Weber BL, Seigler HF, Darrow TL, Paterson H, Marais R, Marshall C], Wooster R, Stratton MR, Futreal PA: Mutations of the BRAF gene in human cancer. Nature 2002, 4I7:949-54.

5. Hoshino R, Chatani Y, Yamori T, Tsuruo T, Oka H, Yoshida O, Shimada Y, Ari-i S, Wada H, Fujimoto J, Kohno M: Constitutive activation of the $4 \mid-/ 43-k D a$ mitogen-activated protein kinase signaling pathway in human tumors. Oncogene 1999, 18:813-22.

6. McPhillips F, Mullen P, Monia BP, Ritchie AA, Dorr FA, Smyth JF, Langdon SP: Association of c-Raf expression with survival and its targeting with antisense oligonucleotides in ovarian cancer. $\mathrm{Br}$ J Cancer 200I, 85: I753-8.

7. Hormaeche C, Khan CMA: Concepts in Vaccine Development, Recombinant bacteria as vaccine carriers of heterologous antigens,. Walter de Gruyter, Berlin and New York 1996:327-349.

8. Shata MT, Stevceva L, Agwale S, Lewis GK, Hone DM: Recent advances with recombinant bacterial vaccine vectors. $\mathrm{Mol}$ Med Today 2000, 6:66-71.

9. Gentschev I, Dietrich G, Goebel W: The E. coli alpha-hemolysin secretion system and its use in vaccine development. Trends Microbiol 2002, 10:39-45.

10. Nishimura A, Morita M, Nishimura $Y$, Sugino $Y$ : A rapid and highly efficient method for preparation of competent Escherichia coli cells. Nucleic Acids Res 1990, 1 8:6169.

II. Dagert M, Ehrlich SD: Prolonged incubation in calcium chloride improves the competence of Escherichia coli cells. Gene 1979, 6:23-8.

12. Bonner TI, Oppermann H, Seeburg P, Kerby SB, Gunnell MA, Young $A C$, Rapp UR: The complete coding sequence of the human raf oncogene and the corresponding structure of the c-raf- $I$ gene. Nucleic Acids Res 1986, 14:1009-15.

13. Gentschev I, Mollenkopf H, Sokolovic Z, Hess J, Kaufmann SHE, Goebel W: Development of antigen-delivery systems, based on the Escherichia coli hemolysin secretion pathway. Gene 1996, 179:133-140.

14. Laemmli UK: Cleavage of structural proteins during the assembly of the head of bacteriophageT4. Nature 1970, 227:680-5

15. Kerkhoff E, Fedorov LM, Siefken R, Walter AO, Papadopoulus T, Rapp UR: Lung-targeted expression of the c-Raf-I kinase in transgenic mice exposes a novel oncogenic character of the wild-type protein. Cell Growth Differ 2000, I I:I85-90.

16. Fedorov LM, Tyrsin OY, Papadopoulos T, Camarero G, Gotz R, Rapp UR: Bcl-2 determines susceptibility to induction of lung cancer by oncogenic Craf. Cancer Res 2002, 62:6297-303.

17. Groux H, Bigler M, de Vries JE, Roncarolo MG: Interleukin-10 induces a long-term antigen-specific anergic state in human CD4+ T cells. J Exp Med 1996, I 84:19-29.

18. Suzuki T, Tahara H, Narula S, Moore KW, Robbins PD, Lotze MT: Viral interleukin I0 (IL- I0), the human herpes virus 4 cellular IL- 10 homologue, induces local anergy to allogeneic and syngeneic tumors. J Exp Med 1995, 1 82:477-86.

19. Jager E, Jager D, Knuth A: Clinical cancer vaccine trials. Curr Opin Immunol 2002, 14:178-82.

20. Pasetti MF, Levine MM, Sztein MB: Animal models paving the way for clinical trials of attenuated Salmonella enterica serovar Typhi live oral vaccines and live vectors. Vaccine 2003, $21: 401-4 \mid 8$.

21. Cardenas L, Clements JD: Oral immunization using live attenuated Salmonella spp. as carriers of foreign antigens. Clin Microbiol Rev 1992, 5:328-342.

22. Chatfield S, Roberts M, Li J, Starns A, Dougan G: The use of live attenuated Salmonella for oral vaccination. Dev Biol Stand 1994 82:35-42.

23. Reisfeld RA, Niethammer AG, Luo Y, Xiang R: DNA vaccines suppress tumor growth and metastases by the induction of antiangiogenesis. Immunol Rev 2004, 199: 181-90.

24. Andersen MH, Fensterle J, Ugurel S, Reker S, Houben R, Guldberg P, Berger TG, Schadendorf D, Trefzer U, Bröcker EB, Straten P, RapP
UR, Becker JC: Immunogenicity of constitutively active V599EBRaf. Cancer Res 2004, 64:5456-5460.

25. Fensterle J, Becker JC, Potapenko T, Heimbach V, Vetter CS, Brocker $E B$, Rapp UR: B-Raf specific antibody responses in melanoma patients. BMC Cancer 2004, 4:62.

26. Gentschev I, Dietrich G, Spreng S, Neuhaus B, Maier E, Benz R, Goebel W, Fensterle J, Rapp UR: Use of the $\alpha$-hemolysin secretion system of Escherichia coli for antigen delivery in the Salmonella typhi Ty2 I vaccine strain. IJMM 2004, 294:363-37I.

27. Vogel M, Hess J, Then I, Juarez A, Goebel W: Characterization of a sequence (hlyR) which enhances synthesis and secretion of hemolysin in Escherichia coli. Mol Gen Genet 1988, 21 2:76-84.

28. Wang HG, Miyashita T, Takayama S, Sato T, Torigoe T, Krajewski S, Tanaka S, Hovey L 3rd, Troppmair J, Rapp UR, Reed JC: Apoptosis regulation by interaction of $\mathrm{Bcl}-2$ protein and Raf- $\mathrm{I}$ kinase. Oncogene 1994, 9:275I-6.

\section{Pre-publication history}

The pre-publication history for this paper can be accessed here:

http://www.biomedcentral.com/1471-2407/5/15/prepub
Publish with Bio Med Central and every scientist can read your work free of charge

"BioMed Central will be the most significant development for disseminating the results of biomedical research in our lifetime. "

Sir Paul Nurse, Cancer Research UK

Your research papers will be:

- available free of charge to the entire biomedical community

- peer reviewed and published immediately upon acceptance

- cited in PubMed and archived on PubMed Central

- yours - you keep the copyright 